\title{
Young Production of European Hedgehog in Sweden and Britain
}

\author{
ROZRODCZOSC JEZY W SZWECJI I WIELKIEJ BRYTANII
}

Hans KRISTIANSSON

\begin{abstract}
Kristiansson H. 1981: Young production of European hedgehog in Sweden and Britain. Acta theriol., 26, 34: 504-507 [With 2 figs.]. Mean litter size in Sweden was calculated from enquiries and found to be 5.2 young per female and year. Comparable results from Britain have given 3.7 ; including second litters yield an annual young production of 4.8. A theory on the geographic variation in litter size proposed by Spencer \& Steinhoff in 1968 was tested and was partially supported.
\end{abstract}

[Dept. Animal Ecology. Univ. Lund, Ecology Building, S-22362, Sweden].

\section{INTRODUCTION}

The European hedgehog (Erinaceus europaeus Linnaeus, 1758) is a common species in urban and suburban areas in most parts of Europe. In spite of this, little information is available on demography of hedgehog populations. Some information is, however, available on litter size (B. Morris, 1967; P. A. Morris, 1977). In this paper I present data on litter size of the hedgehog in Sweden. I will also test a theory proposed by Spencer \& Steinhoff (1968). They suggested that the shorter seasons of more northern latitudes or higher altitudes, limit the number of times an animal resident in those areas is able to reproduce in its lifetime compared to its relatives in more southern or lower regions. It should therefore become advantageous for an animal to invest its energy in a few, large, early litters even when doing so reduces both its life expectancy and the total reproductive contribution to a level below the maximum achievable by many small litters.

\section{METHODS}

The data used were obtained in two ways: from enquiries on the distribution and abundance of the hedgehog in Sweden and by personal communications.

The young hedgehogs leave the nest at an age of three to four weeks, but remain together before being weaned, usually within $38-44$ days of birth (Ranson, 1941). The records used in this paper refer to observations of young when leaving the nest up to weaning, i.e., young at an age of three to six weeks.

\section{RESULTS}

Reports on eigthy-five litters were obtained from all over Sweden. The mean litter size was $5.2 \pm 2.0(0.2)$ (mean $\pm \mathrm{SD}, \mathrm{SE}$ ). There was no statistical difference between the different regions in Sweden. However, 
there was a tendency to larger mean litter size in the middle and northern regions of Sweden. The most observed litter size was five $(27 \%)$ and litter sizes ranged from one to eleven (Fig. 1). Litter sizes from three to seven $(3,4,5,6)$ constituted $72 \%$ of the reports.

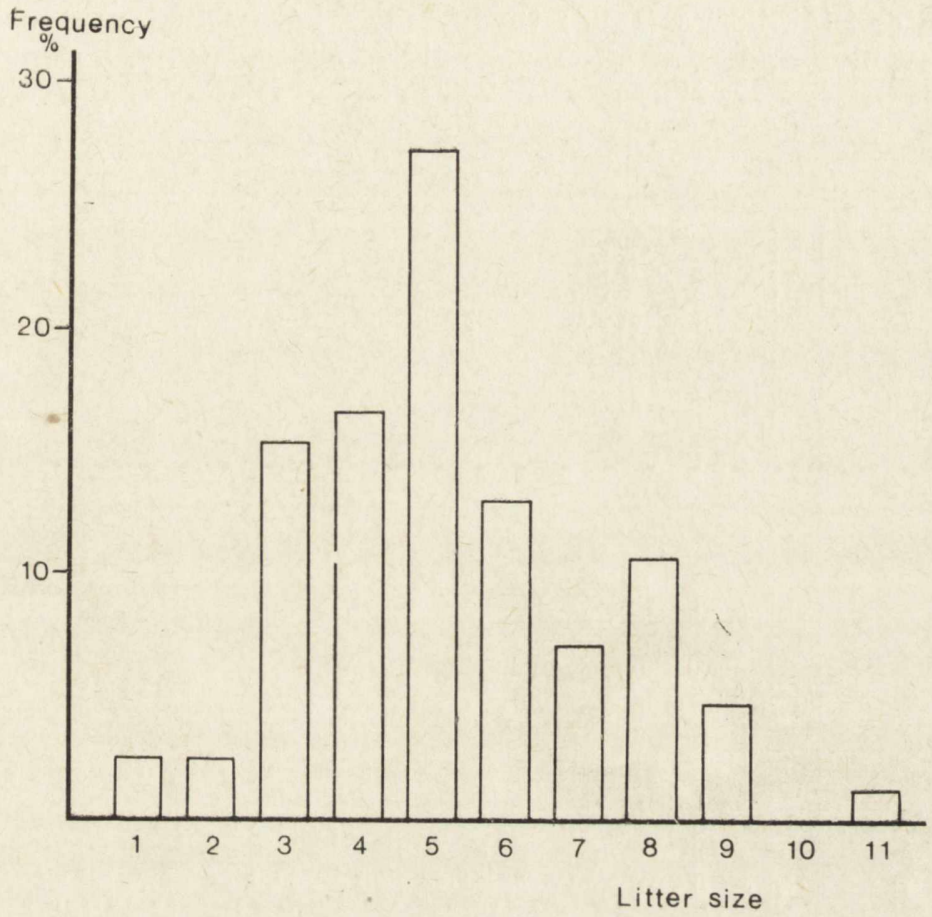

Fig. 1. The distribution of observed litter sizes in Sweden. Mean litter size was $5.2, \mathrm{SD}=2.0$ and $\mathrm{N}=85$.

\section{DISCUSSION}

The figures obtained on litter size in Sweden can be compared with corresponding data from Britain obtained in the same way (Morris, 1977). The mean size of litters at an age of three to six weeks was 3.7 (Fig. 2). The value differs from that in Sweden $(\mathrm{p}<0.001, \mathrm{df}=126$, twotailed Student's $t$-test). Not only is mean litter size larger in Sweden but also the observed range of litter sizes (Fig. 1 and Fig. 2). Some observations from England (Deanesly, 1934; Morris, 1969) indicate, that female hedgehogs can produce two litters per year, but it is not known how often this occurs. In Sweden, second litters are unknown and due to the short season, it is hardly possible for a female to produce a second litter. A rough estimate of the "maximum" extent of second litters in England can be obtained from Deanesly's data (1934): from morphological results some $29 \%$ (nine out of 31 ) of the females that have had one litter had the potential of producing a second litter. If we assume that the first and the second litter are 
affected to the same degree by mortality $(20 \%$ of the prenatal litter size up to the age of one month - Morris, 1977), and that both have the same prenatal litter size, then, the annual juvenile production per female would amount to 4.8. This estimate indicates a lower annual production per female in Britain than in Sweden.

Spencer \& Steinhoff's (1968) theory may be applied in a comparison between Sweden and Britain. One would expect that the harsher climate

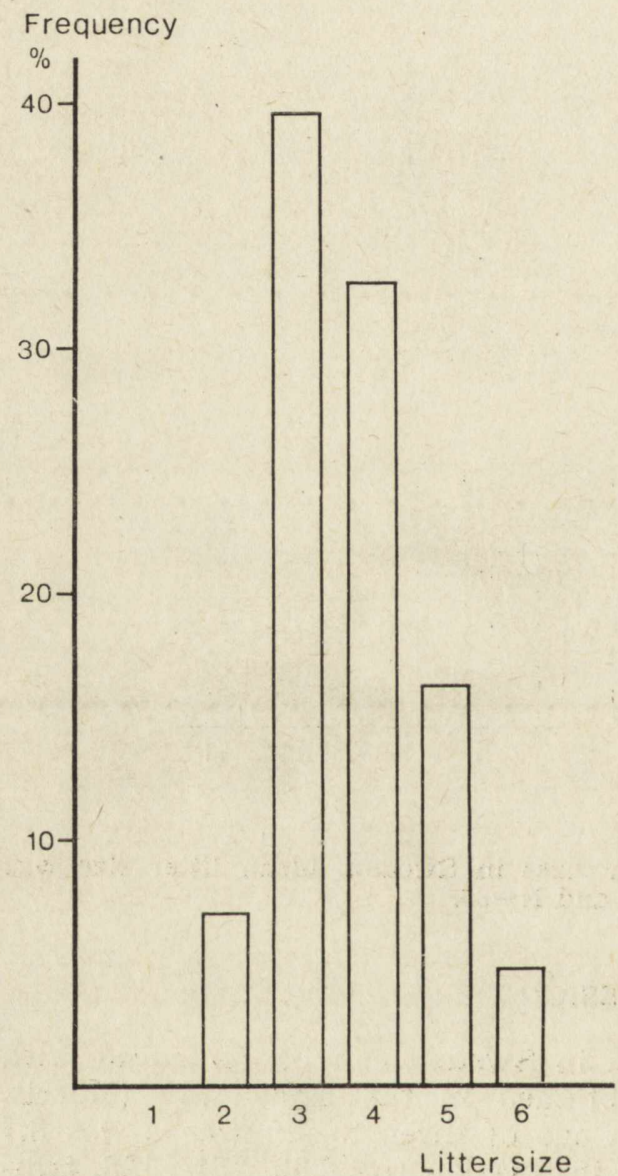

Fig. 2. The distribution of observed litter sizes in England (Morris, 1977). The categories "late young" and "seen" are pooled and correspond to the Swedish reports. Mean litter size was 3.2 , $\mathrm{SD}=1.0$ and $\mathrm{N}=43$.

of Sweden restricted the breeding season. The length of the main breeding season is about four months in England (Morris, 1969), and about two months in Scania; South Sweden (Kristiansson, pers. obs.). The shorter breeding season in Sweden limits the number of times a female can reproduce in a given season and in a lifetime, and thus phenotypes which produce a few, large litters should be favoured. In Britain, with the longer breeding season, phenotypes which produce many and smaller litters would be favoured. The data presented here agree with these predictions. One consequence of the theory is that 
the life expectancy should be shorter in Sweden than in Britain. Morris (1969) calculated life expectancy at weaning for a hedgehog population in England to be 1.9 years. Using capture-recapture data from a population in Scania I have found the corresponding value to be slightly more than two years i.e. almost the same (Kristiansson, unpubl.), which does not agree with the predictions made by Spencer \& Steinhoff (1968).

Acknowledgements: I thank Drs Sam Erlinge and Johnny Karlsson for comments on the manuscript. Mr. Jonathan Thorntorn corrected my English. The study was supported by the Swedish Society for the Conservation of Nature and World Wildlife fund.

\title{
REFERENCES
}

Deanesly R., 1934: The reproductive processes of certain mammals. Part 6: The reproductive cycle of the female hedgehog. Phil. Trans. Lond. Ser. B., 223: 239-276. - Morris B., 1967: The European hedgehog. [In: The UFAW Handbook on the care and management of laboratory animals]. 3rd ed. E. \& S. Livingstone Ltd: 478-488. Edinburgh. - Morris P. A., 1969: Some aspects of the ecology of the hedgehog (Erinaceus europeaus L.) Ph. D. Thesis. University of London. Morris P. A., 1977: Pre-weaning mortality in the hedgehog (Erinaceus europaeus L.). J. Zool., Lond, 182: 162-167. - Ranson R. M., 1941: New laboratory animals from wild species. Breeding a laboratory stock of hedgehogs (Erinaceus europaeus L.). J. Hyg. Camb., 41: 131-138. - Spencer A. W. \& Steinhoff H. W., 1968: An explanation of geographic variation in litter size. J. Mammal. 49: 281-286.

Accepted, May 14, 1981.

\section{Longevity Record for the Lesser Horseshoe Bat}

\author{
REKORDOWY WIEK PODKOWCA MAEEGO
}

Wincenty HARMATA

\begin{abstract}
Harmata, W., 1981: Longevity record for the lesser horseshoe bat. Acta theriol., 26, 34: 507 .

A ringed individual of Rhinolophus hipposideros (Bechstein, 1800) was recaptured 21 years, 3 months and 16 days after the ringing date.

[Dept. Zoopsych. Ethol. Anim., Jagiellonian Univ., Karasia 6, 30-060 Kraków].
\end{abstract}

A female lesser horseshoe bat, Rhinolophus hipposideros (Bechstein, 1800), with ring No. 8785 Inst. Psych. Anim. Univ. Kraków Polon. was caught on December 20th 1980 at Nietoperzowa Cave near Ojców $\left(50^{\circ} 11^{\prime} \mathrm{N}, 19^{\circ} 46^{\prime} \mathrm{E}\right)$. The bat was hanging at a height of $1.5 \mathrm{~m}$ on the cave wall, about $100 \mathrm{~m}$ from the entrance, and there were another individuals near it. The bat had been ringed on Nov. 4th 1959 in the Czerna monastery near Krzeszowice, about $15 \mathrm{~km}$ from the place at which it was found again. The animal had thus lived for 21 years, 3 months and 16 days from the date of ringing. The greatest age hitherto known, established in the same way, was 18 years and 3 months (Gaisler J. \& Hanak V., 1969: Acta Sci. Nat. Acad. Sci. Bohemosl., 3, 5: 3-33).

Accepted, June 10, 1981 